\title{
Applying of Pressing Technology to Forming Finger-Joint Profile for Wood Splicing
}

\author{
Olga Rubleva ${ }^{1, *}$ \\ ${ }^{1}$ Vyatka State University, Department of Machinery and Wood Technology, Moskovskaya st., 36, \\ Kirov, 610000, Russian Federation
}

\begin{abstract}
Splicing of wood lengthwise is widely used in the manufacture of various products. The basic method of forming the finger joint profile is milling. This method has a number of disadvantages: high cost of the milling tool, necessity of its periodic sharpening; high energy consumption of the milling process, design constraints on the geometric parameters and strength of fingers (tenons). An alternative to milling is a new way of forming such joints elements as mortise and tenons by pressing along the grain. This method allows obtaining mortises in the form of fairly accurate rectangular imprints on the ends of the blanks. The use of a punching tool instead of a cutting one avoids chips and reduces the cost of the aspiration system. Previously, rectangular tenons were used only for L-type box joints. The aim of the study is to prove the possibility of using the cold end pressing technology to form the mortises and tenons profile for end joining that meet regulatory requirements. A series of experiments on pressing the elements of joints profile in the form of multiple tenons has shown that the achieved accuracy and roughness meet the requirements for the manufacture of joints intended for lengthwise splicing. Assessment of the strength of the joints showed their compliance with the regulatory requirements. The conducted research confirms confirms the possibility of using the pressing technology to form the profile of the finger joint for wood splicing.
\end{abstract}

\section{Introduction}

Wood is an excellent structural material for the manufacture of various household and industrial products, including furniture, windows, doors, building parts. Its peculiarity as a natural material is a high variability of properties associated with the presence of natural defects such as knots and cracks. To increase the strength of the pieces of wood, these defects are removed, and the resulting workpieces are glued parallel to the grain. Finger joints with relatively sharp or blunt tips are the most prevalent splicing method $[1,2]$; for the same purposes, rectangular tenons can be used [3-6].

The most used technique of forming a joint profile is milling [1, 2]. The disadvantages of this technology are the high cost of the cutting tool, the cost of its periodic sharpening; increased energy consumption of the milling process associated with the need to remove

*Corresponding author: olga_ru@vyatsu.ru 
chips; constructive restrictions on the geometric parameters of the profile [7] and the resulting decrease in strength. Joints with extremely sharp tips having the highest strength up to $75-83 \%[1,8]$ are difficult to obtain under production conditions due to overheating of the sharp edges of the cutting tool. This does not allow fulfilling the recommendations for the length of the glue line, equal to $10-15$ of workpiece thicknesses [1], and the corresponding slope (angle of cutting the fibers) equal to $1 / 10-1 / 15$ (from $5.7^{\circ}$ to $3.8^{\circ}$ )., The angle of fiber cutting is often much larger: for example, finger with parameters $10 \times$ $3.8 \times 0.8 \mathrm{~mm}$ (length $\times$ finger pitch $\times$ tip thickness) have a fiber cutting angle of more than $8.5^{\circ}$, and finger with parameters $12 \times 6.2 \times 0.8 \mathrm{~mm}$, has an even greater angle of $12.7^{\circ}$ [9].

Milling of joint profile with rectangular mortises and tenons (like L-type box joints) also has a number of peculiarities. In the manufacture of rectangular mortises and tenons used for splicing, the critical indicator is the accuracy of their formation. The slightest deviations in the tenon size of a few tenths of a millimetre, caused by inaccuracy of assembly or sharpening of cutting tool, can significantly reduce the tightness of fit and strength characteristics of the joints [10-12].

To partially eliminate these disadvantages, a cold or hot combined method of forming a joint profile by inserting a punch into the ends of the workpieces can be used $[2,13]$. These studies are devoted to obtaining finger joint profiles with a trapezoidal cross-sectional profile by pressing in transverse direction. In order to improve the quality of process of wood pressing when forming a finger, it is advisable on the first step to preshape the fingers by using saws. When using this method, the costs for the cutting tool preparing and waste transporting are reduced. At the same time, there are the following disadvantages: energy consumption for heating the tool, complication of the technological process due to the additional preliminary sawing operation, as well as restrictions on the shape and size of the fingers, depending on deformative properties of wood in transverse direction [2]. For most commercial breeds, the maximum value of deformation during compression in transverse direction will not exceed $70 \%[13,14]$; this makes it impossible to form relatively sharp and long fingers $[2,13]$. In this regard, the method of punching fingers in the places of preliminary cuts is focused mainly on the manufacture of non-structural joints.

The study [15] shows the possibility of forming single rectangular indentations at the ends of the blanks by local pressing along the wood fibers (fig. 1).

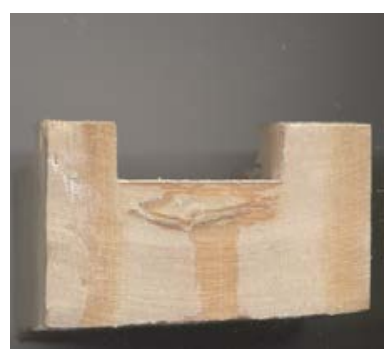

(a)

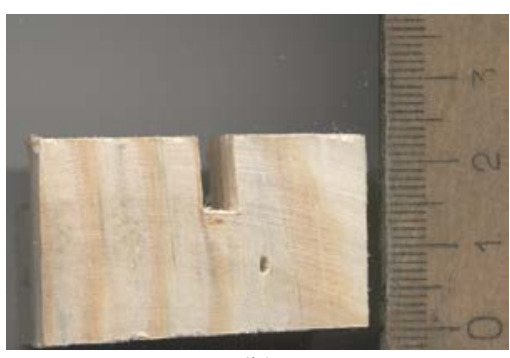

(b)

Fig. 1. Some examples of mortises obtained by inserting the punch parallel to grain: (a) width of mortise $B=20 \mathrm{~mm}$, depth of mortise $h_{n}=8 \mathrm{~mm}$; (b) $B=4 \mathrm{~mm}, h_{n}=11 \mathrm{~mm}$; the scale of figure (b) is valid for the rest of figures

A metal punch with a profile corresponding to the desired joint profile moves into the the end of the workpiece, in the longitudinal direction of wood. Sections of wood located under the working plane of the punch start in deform plastically. When the punch moves into the depth of the workpiece, sliding planes of the lateral edges of the tool are formed, which form the edges of the mortise. At the end of the process, under each of the working planes of the punch, the bottom of the mortise is formed, and under it there is a "core" of 
densified wood. The dimensions of the "core" are commensurate with the depth of the mortise [15]. The elastic recovery of the deformed zone is no more than $4 \%$.

Resulting indentations have high accuracy and surface quality [15] and can potentially be used as mortises in multiple mortise-and-tenon joints (their appearance is similar to the profile of box connections).

So, the aim of our study is to to prove the possibility of using the technology of cold local pressing in longitudinal direction to form the profile of joints for wood splicing that meet the requirements of regulatory documents.

\section{Materials and methods}

\subsection{Materials}

The research was carried out on the example of a typical for central Russia coniferous species - pine. Samples were made from mixed sawn timber. For experimental studies, workpieces were selected that did not contain knots and cracks in the pressing zone and had a predominantly tangentially oriented face. The dimensions of the section of the workpieces are $25 \times 40 \mathrm{~mm}$, the moisture content is from 5 to $9 \%$.

For gluing, we used adhesives based on a polyvinyl acetate dispersion of the brands of PVA Super (Akron), Moment Stolyar (Henkel Rus), Titebond II Premium (Franklin International).

\subsection{Methods}

The forming of finger joints profiles was carried out on P-10 (ZIM) and T61210M (AE\&T) laboratory presses, supplemented with a set of specially made equipment for basing, fixing and crimping the blanks. Specially made punches had profiles corresponding to the profiles of the finger joints (fig. 2). We used punches of various designs (one-piece and assembly) and various size types (tenon thickness from 2 to $4 \mathrm{~mm}$, tenon length from 5.5 to $20 \mathrm{~mm}$, gap (or interference) in the mortise-and-tenon joint from -0.1 to $0.2 \mathrm{~mm}$ ).

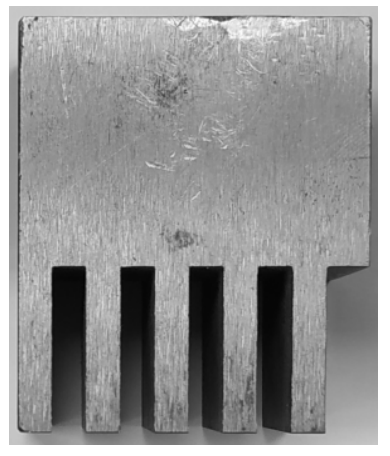

(a)

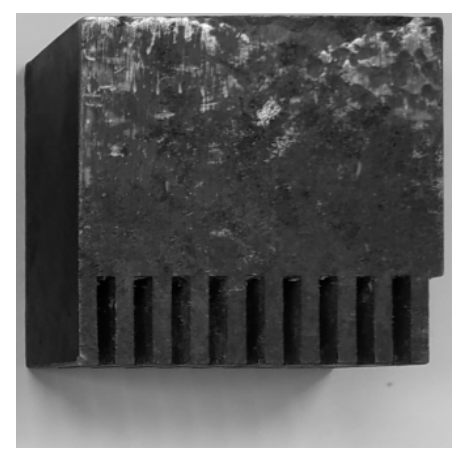

(b)

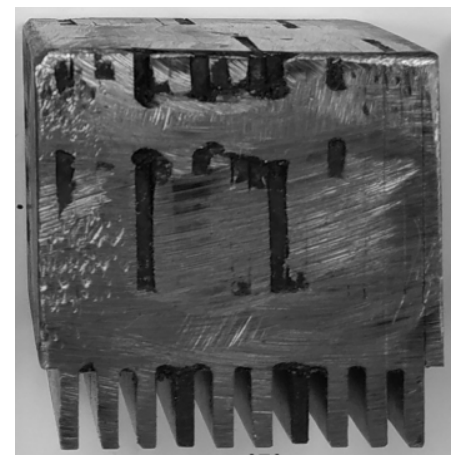

(c)

Fig. 2. Some examples of punches: (a), (b) one-piece punche; (c) assembly punche from a set of plates connected by welding

The strength characteristics of the joints were determined in accordance with the normative documentation for adhesive joints: GOST 15613.4-78 and GOST 33120-2014. The tests were carried out on a universal testing machine UMM-5 (ZIM) and a tensile 
testing machine R-5 (ZIM). The ANOVA technique was used to study the relationship between the obtained data on the parameters and strength of joints [6].

\section{Results and discussion}

\subsection{Working accuracy and surface roughness of pressed joint profiles}

We have carried out a series of experiments on pressing joint elements in the form of multiple tenons (Fig. 3 (a)). Identation with a high degree of accuracy follows the profile of the punch. The accuracy of the mortise dimensions formed by the tool 11 of the accuracy grade corresponds to a grade of not less than 12 in width and not less than 13 in depth. Surface roughness is not more than $\mathrm{Rm} \max =86 \mu \mathrm{m}$ [15]. This exceeds the requirements for the working accuracy for rectangular mortises and tenons given in the standards and technical literature [16-18]. The obtained joint details of two size types also had an accuracy of the tenons at least grade 13, which corresponds to the requirements for the manufacture of joints for splicing [19].

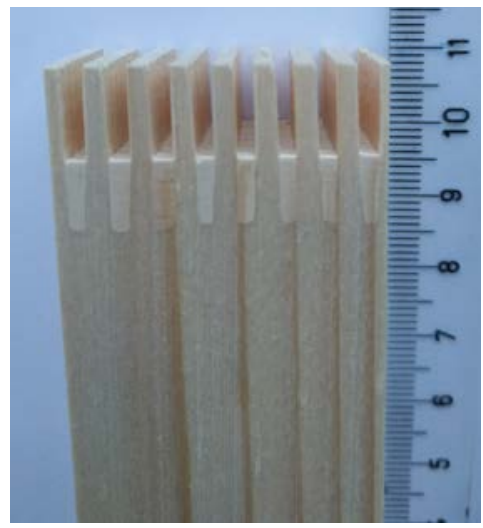

(a)

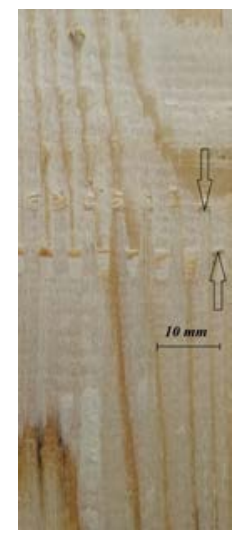

(b)

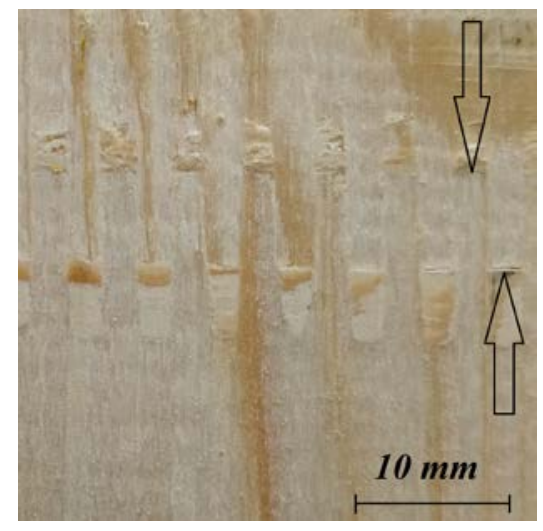

(c)

Fig. 3. The appearance of the blanks: (a) with pressed pins; (b) glued lengthwise; (c) the area of the glue line; arrows indicate the tops of the spikes and the bottom of the lugs

\subsection{Estimation of strength of end joints}

The details of the finger joints were glued along the grain (fig. 3 (b), (c)) on an polyvinyl acetate dispersion adhesive and then subjected to tensile and bending strength tests [6].

To estimate the strength of the joints, we suggested the indicator "relative strength". It is the ratio of the bond strength to the strength of solid wood. Fig. 4 shows the box-plots obtained from the strength test results for joints with a tenon length of $10 \mathrm{~mm}$ and a tenon thickness of $2 \mathrm{~mm}$. The average relative bending strength reaches $80.2 \%$, and average relative tensile strength reaches $59.5 \%$. These values correspond to the requirements of state standards GOST 20850-2014, GOST 33080-2014, GOST 33081-2014 for C30 grade sawn timber and for K36 grade wooden glued structures. This confirms the possibility of using pressed rectangular multiple tenons for the manufacture of end joints for splicing in joinery and other products in accordance with GOST 24700-99, GOST 30972-2002. 


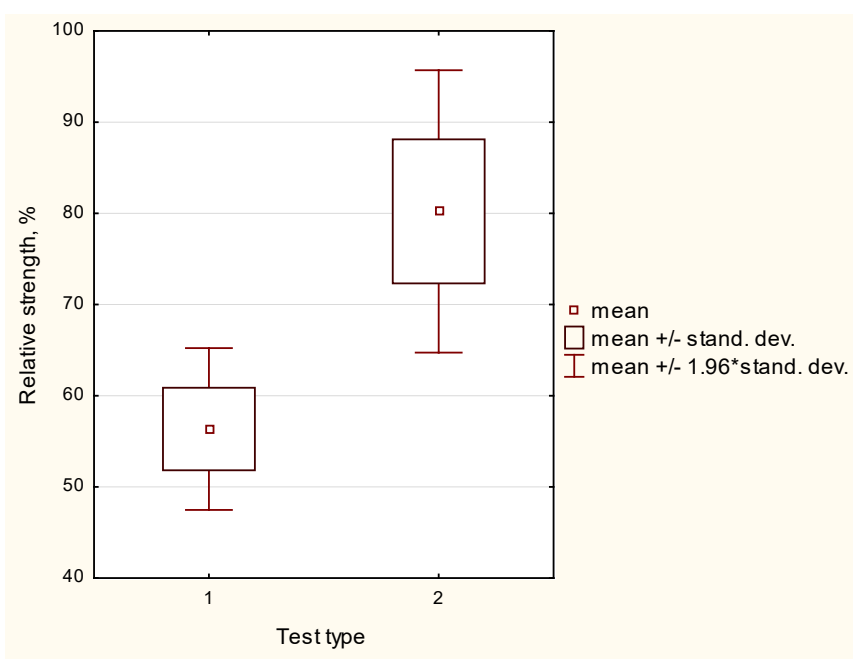

Fig. 4. Box-plots for two tests: (1) tensile strength; (2) bending strength

We believe these results have been achieved both by decrease in absorption of the mortise bottom associated with the densification of wood [15], and by the high manufacturing precision of identations (mortises), which is one of the key criteria for achieving high strength of glued joints $[7,17,20]$.

\section{Conclusion}

The use of a new method of local pressing in longitudinal direction provides formation of high quality finger-joint profile with rectangular mortises and tenons.

Using of punching tool allows providing high manufacturing precision in the manufacture of profile, low surface roughness and achieving a densification of wood at the bottom of the mortises, which reduces the absorption and consumption of the glue.

Glue end joints on pressed tenons have a sufficiently high strength and meet the requirements of standards for glued wooden products.

The technological process for the manufacture of glued joints on pressed mortises and tenons, based on method of local pressing in longitudinal direction, can be recommended for the production of joinery, furniture and other products.

\section{References}

1. V.N. Volynskij, Tekhnologiya kleenyh materialov [Technology of glued materials], 392 p. (In Russ.) (St. Petersburg, PROFIKS Publ., 2008)

2. R.W. Jokerst Finger-Jointed Wood Products, 26 p. (Forest Products Lab Madison Wi, №. FSRP-FPL-382, 1981)

3. A.A. Bartashevich, S.P. Trofimov, Konstruirovanie mebeli [Furniture construction], 336 p. (In Russ.) (Minsk, Sovremennaya shkola Publ., 2006).

4. A. Guidice, The seven essentials of woodworking, 128 p. (Sterling, 2001)

5. O.A. Rubleva, Sposob formirovaniya ehlementov shipovyh soedinenij derevyannyh zagotovok [Method of finger joint's shaping in wood blanks], Patent RF № $\mathbf{2 4 7 1 6 1 4}$ (In Russ.) (2013) 
6. O.A. Rubleva, A.G. Gorokhovsky, Experimental evaluation of strength of end joints with rectangular pressed fingers, Lesnoy Zhurnal [Russian Forestry Journal] no. 3, pp. 128-142 (2020) DOI: 10.37482/0536-1036-2020-3-128-142

7. O.A. Rubleva, A.G. Gorokhovsky, Prochnost' skleivaniya drevesiny po dline na pryamougol'nye shipy [Strength Of End Joints Whith Rectangular Fingers] (In Russ.), Conifers of the boreal area, v. XXXVII, iss. 5, pp. 358-366 (2019)

8. M. Vrazel, Jr T. Sellers, The effects of species, adhesive type, and cure temperature on the strength and durability of a structural finger-joint, Forest products journal, v. 54, iss. 3, pp. 66-76 (2004)

9. Frezy dlya srashchivaniya [Splicing Cutters], available at: http://stanokspb.ru/instrument/frezy-nasadnie/frezyi_dlya_srashhivaniya/ (In Russ.) (accessed 25 December 2018)

10. N. Tankut, The effect of adhesive type and bond line thickness on the strength of mortise and tenon joints, International journal of adhesion and adhesives, v. 27, iss. 6 , pp. 493-498 (2007) DOI: 10.1016/j.ijadhadh.2006.07.003

11. E. Likos, E. Haviarova, C.A. Eckelman, Y.Z. Erdil, A. Ozcifci, Effect of tenon geometry, grain orientation, and shoulder on bending moment capacity and moment rotation characteristics of mortise and tenon joints, Wood and Fiber Science, v. 44, iss. 4, pp. 462-469 (2012)

12. Y.Z. Erdil, A. Kasal, C.A. Eckelman, Bending moment capacity of rectangular mortise and tenon furniture joints, Forest Products Journal, v. 55, iss. 12, pp. 209 (2005)

13. M. D. Strickler, Finger jointing of lumber, U.S. Patent No. 3,262,723 (1966)

14. P.N. Huhryanskij, Pressovanie drevesiny [Wood pressing], 352 p. (In Russ.) (Moscow, Lesnaya promyshlennost' Publ., 1964)

15. O. A. Rubleva, Structural changes of Scots pine wood caused by local pressing in the longitudinal direction, Drewno, v. 62, iss. 204, pp. 23-39 (2019) DOI: 10.12841/wood.1644-3985.268.06.

16. GOST 9330-2016 Osnovnye soedineniya detalej iz drevesiny i drevesnyh materialov. Tipy i razmery [State Standard 9330-2016. Principal joints of details of wood and wooden materials. Types and dimensions], 16 p. (In Russ.) (Moscow, Standartinform Publ., 2017)

17. L.I. Radchuk, Osnovy konstruirovaniya izdelij iz drevesiny [Basics of designing wood products], 200 p. (In Russ.) (Moscow (MSFU Publ., 2006)

18. GOST 19414-90 Drevesina kleenaya massivnaya. Obshchie trebovaniya $k$ zubchatym kleevym soedineniyam [State Standard 19414-90 Solid glued wood. General requirements for glued finger joints], 7 p. (In Russ.) (Moscow, IPK Izdatel'stvo standartov Publ., 1990)

19. GOST 19414-90 Drevesina kleenaya massivnaya. Obshchie trebovaniya $k$ zubchatym kleevym soedineniyam [State Standard 19414-90 Solid glued wood. General requirements for glued finger joints], 7 p. (In Russ.) (Moscow, IPK Izdatel'stvo standartov Publ., 1990)

20. I. Džinčić, D. Živanić, The influence of fit on the distribution of glue in oval tenon / mortise joint, Wood Research, v. 59, iss. 2, pp. 297-302 (2014) 